\title{
MODELLING AND SIMULATION FOR PRODUCTION LOGISTICS SYSTEM IN INDUSTRIAL ENTERPRISES BASED ON HYBRID NETWORK
}

\author{
Xiao, N. ${ }^{*, * *}$; Ni, C. D. ${ }^{* *, \# ~ \& ~ G u o, ~ S . ~ J . * ~}$ \\ *Business school, Central South University, Changsha, Hunan 410083, China \\ ** School of Economics, Shenzhen Polytechnic, Shenzhen, Guangdong 518055, China \\ E-Mail: nichidan@szpt.edu.cn ( ${ }^{\#}$ Corresponding author)
}

\begin{abstract}
Modern industrial production logistics systems in a modern are very complicated, which generally includes many continuous variables and discrete events. For these complicated industrial production logistics systems, this paper has set up a new hybrid Petri network model based on the common hybrid Petri network and with a combination of differential Petri net and controlled Petri net. This paper made simulation calculation with Java language and studied the modelling object through an industrial DFM solvent recovery process, which has revealed that this model is suitable for the modelling and simulation of hybrid production logistics system in industrial enterprises and can unify the simulation and analysis under the framework of one model. Targeted control strategies can be proposed based on simulation results, which is of great significance in instructing and improving production efficiency.

(Received, processed and accepted by the Chinese Representative Office.)
\end{abstract}

Key Words: Hybrid Petri Net, Production Logistics, Modelling, Simulation

\section{INTRODUCTION}

Industrial enterprises have been the important basic industries of our economic development, which include chemical industry, metallurgy, petroleum, steel, energy, paper and food production, etc., while these enterprises are also important in our energy consumption and environmental pollution emissions. Therefore, how to decrease energy consumption and decrease the pollution of these enterprises has been a major focus in industrial field research. Each industrial enterprise has its own production logistics system, which is the basis for maintaining continuity of the production process [1] and is an essential process in manufacturing. Characteristics of each process of production logistics system in industrial enterprises have been studied, including material conversion and the migration rule etc., in order to make optimization based on its characteristics, which is an effective measure of improving resource utilization rate, production efficiency and environmental improvement.

Production logistics system of industrial enterprises involve numerous and complicated factors with mutual effects. Many systems in the industrial field are generated with interaction between the dynamic system of continuous variables and the dynamic system of discrete events, which is the so-called hybrid system. The traditional method cannot make analysis and simulation for the hybrid system accurately and clearly. In recent years, hybrid Petri net (HPN) technology developed from the traditional Petri net and has more image, objective and flexible characteristics, which is an obvious advantage and significant for hybrid industrial production logistics system [2]. Furthermore, it can describe a discrete event and continuous event at the same time. Fabio et al. have proposed the first order hybrid Petri net for optimization and control of the hybrid system [3]. Flaus and Ollagnon have proposed the hybrid flow network (HFN) for simulation of industrial production logistics with a combination of Petri net and continuous process net [4]. Paper [5] combines speed controlled Petri net and controlled timed Petri net to establish the hybrid controlled Petri net model and applies it to the industrial evaporation process. Zhao et al. [6, 7] have made a series of 
modelling simulation research on the steel production logistics system in steel enterprises with hybrid Petri net. Zhang and Wang $[8,9]$ have set up the energy prediction and simulation model of energy loss in production logistics systems with a combination of timed hybrid Petri net and continuous Petri net. Wang et al. [10] have made simulation and optimized the process flow of the aircraft assembly line based on timed Petri net.

For the industrial production logistics hybrid system, this paper has made modelling and simulation for the production logistics system with adoption of hybrid Petri net technology and taken one chemical solvent recovery process as the background to make research and simulation, which has revealed that adopting the hybrid network to make modelling and simulation for industrial production logistics is an effective method for improving production efficiency and resource utilization rate.

\section{HYBRID PETRI NET (HPN) MODEL}

Petri net is a graphical mathematical analysis tool, which was first proposed by German scientist Carl Adam Petri in 1962 [11]. With the continuous expansion of production logistics systems, the traditional common Petri net is very difficult to analyse [12]. Therefore, Petri net needs to be expanded, which include Petri net, controlled Petri net, coloured Petri net and random Petri net, etc. On this basis, hybrid Petri net has been proposed firstly by Bail et al. [13], which consists of common Petri net and continuous Petri net and can describe integer variables, real variables and symbolic variables in the hybrid system. Hybrid Petri net has been further developed in the following, and different hybrid network programs have been proposed worldwide, such as batch Petri net [14, 15], differential Petri net [16], programmable and timed Petri net [17] and first order hybrid net [18], etc.

This paper has set up a new hybrid Petri network model on the basis of common hybrid Petri net and combining differential Petri net and controlled Petri net together and unified simulation and analysis under one model framework.

\subsection{Basic definition of hybrid Petri}

The definition of hybrid Petri net established in this paper is as follows:

Define hybrid Petri net as 7 tuple:

$$
H P N=\left\{P, T, M, D, F, W, M_{0}\right\}
$$

where, $P$ is the set of limited library, expressed as:

$$
P=P^{S} \cup P^{C}
$$

In the formula, $P^{s}=\left\{p_{1}^{s}, p_{2}^{s}, \ldots, p_{n}^{s}\right\}(n>0)$ is a finite set of state library and expressed as $\circ$; $P^{k}=\left\{p_{k}^{s}, p_{k}^{s}, \ldots, p_{k}^{s}\right\}(k>0)$ is a finite set of control library and expressed; all the libraries has infinite capacity.

$T=\left\{t_{1}, t_{2}, \ldots, t_{i}\right\}(i>0)$ is transition finite set and transmission.

Library and transmission have the following relationship, as shown in Eqs. (2) and (3):

$$
p^{S} \cap T=\Phi, p^{S} \cup T \neq \Phi
$$

$M$ is the set of dynamic marking and is expressed as:

$$
M=M^{S} \cup M^{C}
$$

In the formula, $M^{s}=\left\{m_{1}^{s}, m_{2}^{s}, \ldots, m_{n}^{s}\right\} \rightarrow R$ is a dynamic labelling set of state library; $M^{c}=\left\{m_{1}^{c}, m_{2}^{c}, \ldots, m_{k}^{c}\right\} \rightarrow R$ is a dynamic labelling set of Diabolo library.

$D$ is a directed arc set connecting library and transition and the expression is:

$$
D=D^{S} \cup D^{C}
$$

In the formula, $D^{s}:\left(p^{s} \times T\right) \cup\left(T \times p^{s}\right) \rightarrow R^{+}$is a transmission directed arc and expressed as $\rightarrow, D^{c}:\left(p^{c} \times T\right) \rightarrow R^{+}$is a control directed arc and expressed as $\rightarrow$. 
$F: T \rightarrow R$ is a function set defined on transmission and the expression is:

$$
f_{j}=v_{j}+\tau_{j}, \forall f_{j} \in F
$$

In the formula, $v_{j}$ is transmission speed, which is usually the linear function of the dynamic marking of library; $\tau_{j}$ is duration time of transmission, which is usually constant.

$W:(P \times T) \cup(T \times P) \rightarrow R_{0}^{+}$is the generalized weight function and is defined on directed arc.

$M_{0}$ is an initial marking set and can be expressed as:

$$
M_{0}=M_{0}^{S} \cup M_{0}^{C}
$$

In the formula, $M_{0}^{s}$ is an initial marketing set of state library and $M_{0}^{c}$ is an initial marking set of control library.

\subsection{Enabling and inspiration of HPN transmission}

Enabling of transmission: if $\forall t_{j} \in T$, when there is control library in the input set, that is $\exists p_{i}^{c} \in{ }^{\circ} t_{j}$; if $m_{i}^{c}(\tau) \geq\left\|w^{c}\left(p_{i}^{c}, t_{j}\right)\right\|$, then $t_{j}$ is enabling at time $\tau$; when there is no control library in the input set, that is $\exists p_{i}^{c} \notin{ }^{\circ} t_{j}$, if $\forall p_{i}^{c} \notin{ }^{\circ} t_{j}$ meets $m_{i}^{s}(\tau) \geq\left\|w^{s}\left(p_{i}^{s}, t_{j}\right)\right\|$, then $t_{j}$ is enabling at time $\tau$.

Inspiration of transmission: if $\forall t_{j} \in T$ then the following two conditions are met: (1) $t_{j}$ is enabling; (2) passing time delay $\tau_{j}$; $t_{j}$ is inspiration and inspiration speed is $v_{j}$.

\subsection{Basic property of hybrid Petri net}

Hybrid Petri net has the following basic properties:

1. Accessibility: initial state $M_{0}$ can achieve target state $M_{n}$ after a series of transmissions and $M_{n}$ can be described as the control state of target, and failure or danger needs to be avoided.

2. Bounded: initial state $M_{0}$ reaches any target state $M_{n}$ through transmission. Both of them are bounded, which reflects dynamic stability of the production logistics hybrid system from another perspective.

3. Activity: if the transmission is made arbitrarily and can be inspired, then the transmission can be regarded as having activity, including transmission inspired by the control of the operator, which affects the operability of the control system from another perspective.

4. Invariant: similar to common Petri net, hybrid Petri net has $P$ invariant and $T$ invariant, which have been defined as the following:

- $P$ invariant: assume $H$ is an incidence matrix, if $X^{T} H=0$, then vector $X \in R^{n}$ is a $P$ invariant;

- $T$ invariant: assume $H$ is an incidence matrix, if $H Y=0$, then vector $Y \in R^{m}$ is a $T$ invariant.

5. Invariant behaviour state: describe the transmission as $v_{j}=\dot{x}(t)=f_{j}(x(t), u)$, if $\forall_{t} \in R$, $x\left(t_{0}\right) \in M \Rightarrow x(t) \in M, M \subset X$ then $M$ is the invariant behaviour state set of hybrid Petri net. The invariant behaviour state can be analysed through an evolution graph, and nodes of the evolution graph correspond to a reachable invariant behaviour state. The connecting arc is expressed as the transmission of an invariant behaviour state, and the evolution graph is the reachable system graph of a discrete event. Therefore, it can adopt the main graph methods of Petri net to analyse. The control strategy in the control process of the production logistics hybrid model can be studied through the analysis of the invariant state.

\subsection{Simulation method of hybrid Petri net}

In the hybrid Petri model, each kind of simulated variable and state information is presented in the system through the marking in the library, and each kind of event is presented through 
inspiration in transmission. The simulation process mainly accomplishes two steps. Firstly, it confirms the transmission which can be inspired in the transmission set based on current marking. Secondly, it confirms the marking evolution process and evolution result of the hybrid system.

In the simulation process, there are two situations for system termination. First is to reach the target marking given by the system. New marking attained from every evolution will be compared with target marking, and when the target marking is achieved, simulation finishes. Secondly is to achieve the simulation time given by system. When making simulation for the actual hybrid system, and the adoption of the termination method is related to the performance and features of the production logistics system, which must be determined by the demand of modelling system.

Simulation calculation process of hybrid Petri net is shown in Fig. 1.

The HPN simulation algorithm in Fig. 1, programed with Java, realizes the main design components in the model through programming based on object oriented thinking. In object oriented thinking, a combined design of data and operation can be realized through class. Library marking, time delay of transmission, inspiration speed and weight coefficient of directed arc are taken as their member variables, and they are designed into the properties of library class and transmission class. At the same time, their operation is packaged through class as member function. Based on above thinking, the simulation algorithm through Java in finally realized.

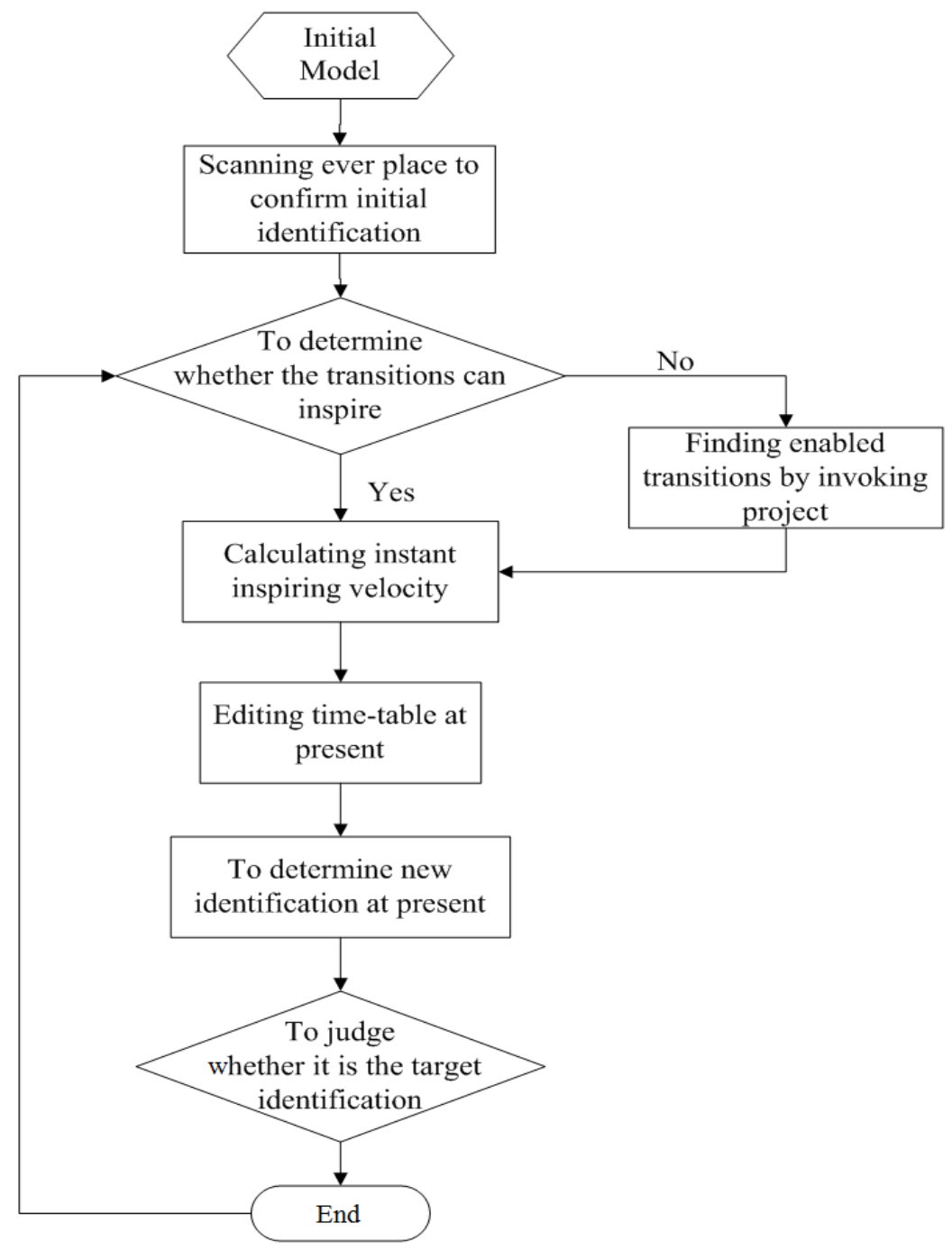

Figure 1: Simulation algorithm for HPN. 


\section{APPLICATION OF HYBRID PETRI NET MODEL}

The above introduced hybrid Petri net model can be applied to modelling and simulation of production logistics systems in industrial enterprises. The following makes modelling and simulation for the evaporation tank process in one chemical solvent recovery.

\subsection{DMF solvent recovery process}

The full name of DMF solvent is dimethylformamide, which is an organic compound widely applied in modern industrial production [19] and is expensive. If the recovery is insufficient, it will be lost in the natural environment of air and rivers etc. and will cause serious pollution [20]. The DMF recovery process system includes a single tower process flow system and a double tower process flow system [21, 22]. The double tower process flow is mainly introduced here, and its process flow chart is as shown in Fig. 2.

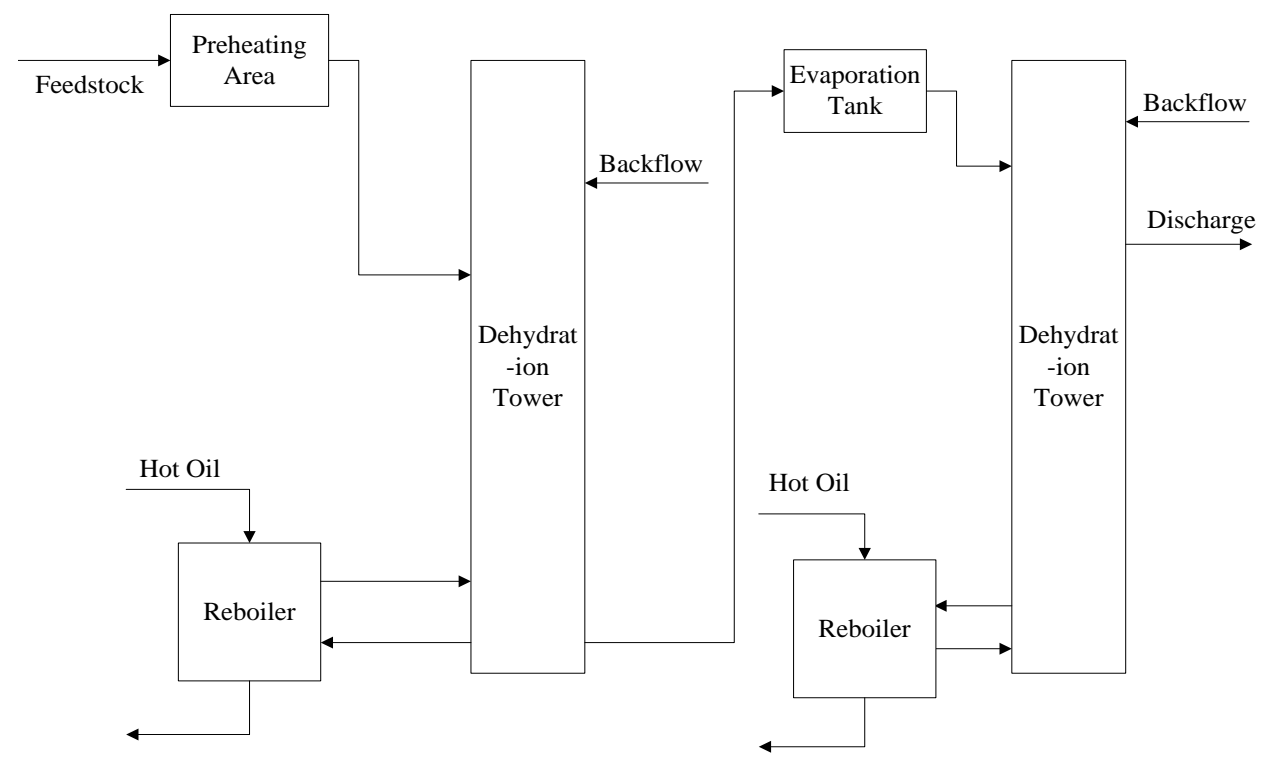

Figure 2: Technological process of DMF recycle.

Generally, waste water with about $25 \%$ DMF produced in one industrial workshop flows into the pre-heater after calculation. Then, the temperature increases to $60^{\circ} \mathrm{C}$ after exchanging heat with steam condensed water in the hot water tank, and then enters into the dehydration tower, entering into the evaporation tank with circulating liquid after dehydration and compression. It is then heated to boil through heat conducting oil and then flash evaporation is made, separating gas and liquid. Liquid enters into circulating pump and gas enters into distillation tower for distillation. DMF solvent is attained to enter into the recycling tank and transport back to the DMF original tank.

It can be learnt from the DMF process that its process is very complicated and is the classic hybrid system, which not only includes many continuous variables (flow, temperature, liquid level and pressure etc.) but also includes discrete pieces of equipment (various pumps, valves and motors, etc.). This paper has made modelling and simulation for the evaporation tank, and the evaporation tank process is shown in Fig. 3. The flow of the original liquid entering into the evaporation tank is controlled through control valve $\mathrm{V}$. at the same time. Liquid in the evaporation tank enters into the heat exchanger through feeding circulating pump PP. The liquid is heated to boil to enter into the top of distillation tank. Flash evaporation is made under a pressurized state and the gas enters into the distillation tower. In the distillation process, the stability of liquid level $L$ in the distillation tank is extremely important, which is always affected by feeding flow $F$, pressure $P$, evaporation temperature $T$ 
and temperature of heat transfer oil $T_{0}$, etc., which makes a large fluctuation appear in the continuous control system and adopts corresponding strategies through network modelling simulation.

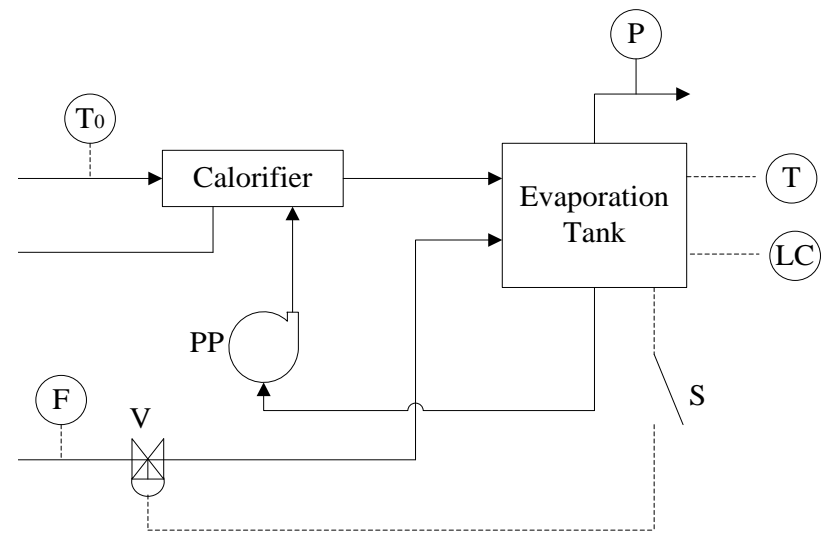

Figure 3: Technological process of DMF evaporation tank.

\subsection{Modelling principle}

To simplify the system, the block modelling method can be adopted for each process unit, and then each block model is combined together. Each model is established based on the following principles: the state of discrete equipment can be expressed with the control library; the changing situation of each continuous variable can be expressed with the transmitted inspiration speed and the continuous time of the operation can be expressed with the time delay of transmission. The parameter of each continuous variable is expressed with the state library.

\subsection{DMF evaporation tank hybrid Petri net model}

The hybrid network model is set up based on the process of the evaporation tank shown in Fig. 3, in which the control equipment of liquid level includes control valve $\mathrm{V}$, feed circulating pump PP and switch S of PID controller. V is divided into several different discrete degrees of opening, and the model is set as Fig. 4.

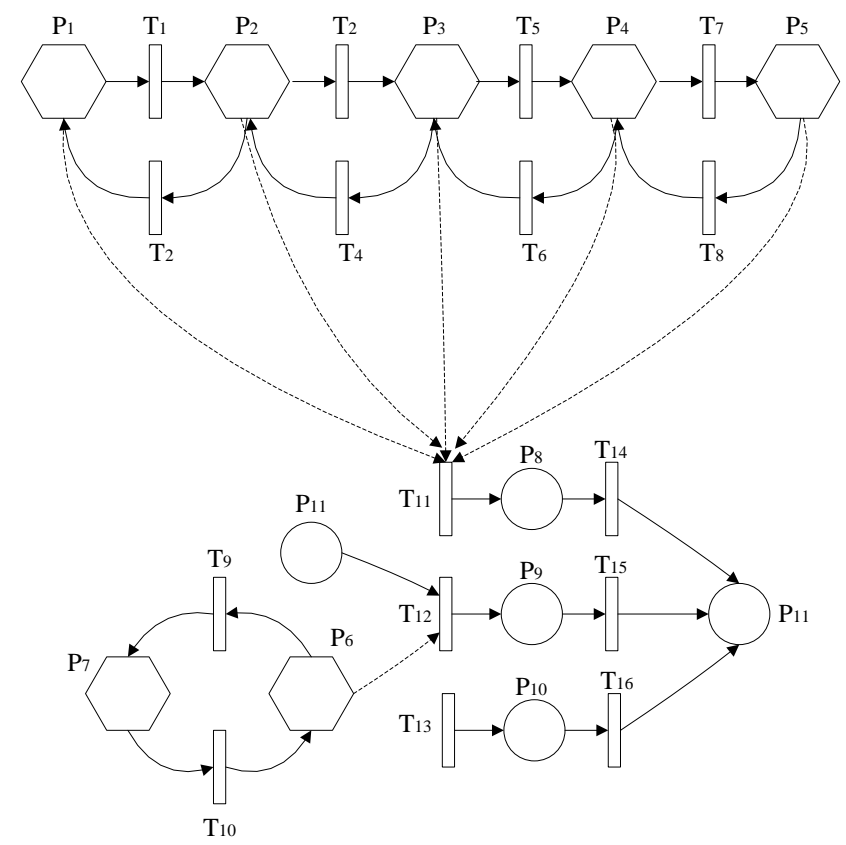

Figure 4: HPN model for DMF evaporation tank. 
The definitions of each library and transmission in hybrid Petri network model in Fig. 4 are shown in Table I and Table II.

Table I: Meanings of control and state places in the HPN model.

\begin{tabular}{|c|l|}
\hline Control Place & \multicolumn{1}{c|}{ Meaning } \\
\hline $\mathrm{P}_{1}-\mathrm{P}_{5}$ & Opening gauge for control valve of flux \\
\hline $\mathrm{P}_{6}$ & State of start or stop for loop heat pump PP \\
\hline $\mathrm{P}_{7}$ & State of start or stop for loop heat pump PP \\
\hline State Place & \multicolumn{1}{c|}{ Meaning } \\
\hline $\mathrm{P}_{8}$ & Charging rate \\
\hline $\mathrm{P}_{9}$ & Temperature of feedstock \\
\hline $\mathrm{P}_{10}$ & Pressure in the tank \\
\hline $\mathrm{P}_{11}$ & Liquid level \\
\hline
\end{tabular}

Table II: Meanings of changes in HPN model.

\begin{tabular}{|c|l|}
\hline Changes & \multicolumn{1}{|c|}{ Meaning } \\
\hline$T_{1}-T_{8}$ & Switchover between different opening gauge of flux control valve \\
\hline$T_{9}-T_{10}$ & Switchover for loop heat pump PP \\
\hline$T_{11}$ & Influence of opening gauge of control valve for flux \\
\hline$T_{12}$ & Influence of state of loop heat pump for feedstock temperature \\
\hline$T_{13}$ & Controlling the pressure in the tank \\
\hline$T_{14}-T_{16}$ & Influence of charging rate, feedstock temperature and pressure in the tank for liquid level \\
\hline
\end{tabular}

\subsection{Simulation results}

The DMF distillation process focuses on the control of liquid level, and the causes of a change in liquid level include system demand and interference appearing in the system. To avoid the fluctuations in liquid level, it must be adjusted through discrete control volume. If the feeding temperature and pressure within the distillation tank remains unchanged, the control of liquid level mainly through the degrees of openness of the flow control valve (the five openness degrees are: $10 \%, 30 \%, 50 \%, 70 \%, 90 \%)$ as well as the start and stop positions of circulating heating pump PP (two states of open or stop).

Set initial marking as $M_{0}=(0,0,1,0,0,1,0,85,150,40,60)$, target marking as $M_{0}=(0,0$, $1,0,0,1,0,85,150,40,100)$. Five programs in the research may achieve target marking:

1. Switch the flow control value $\mathrm{V}$ at openness degrees of $50 \%$ and $70 \%$;

2. Switch the flow control value $\mathrm{V}$ at openness degrees of $50 \%, 70 \%$ and $90 \%$;

3. Change the state of the circulating heating pump;

4. Switch the flow control value V at openness degrees of $50 \%$ and $70 \%$, at the same time; change the state of circulating heating pump;

5. Switch the flow control value V at openness degrees of $70 \%$ and $90 \%$, at the same time; change the state of circulating heating pump.

Summarize the simulation results data of the above five programs and the results are shown in Figs. 5 to 9.

In Figs. 5 to 9, $\mathrm{m} 8, \mathrm{~m} 9$ and $\mathrm{m} 11$ are the marking change of corresponding state libraries P8, P9 and P11 when the control library marking changes, which are feeding amount, feeding temperature and liquid level of the distillation tank. All the main influencing factors of changes in liquid level are included in the hybrid Petri net model and each program has won the evolution process. Comparing the liquid level change curve in Figs. 5 to 9, it can be seen that the fourth program takes the shortest time in achieving target marking. $M_{0}=(0,0,1,0,0$, $1,0,85,150,40,100)$, switch flow control value $\mathrm{V}$ at openness degrees of $50 \%$ and $70 \%$, at 
the same time; change the state of the circulating heating pump. The distillation process can be controlled and adjusted with this program.

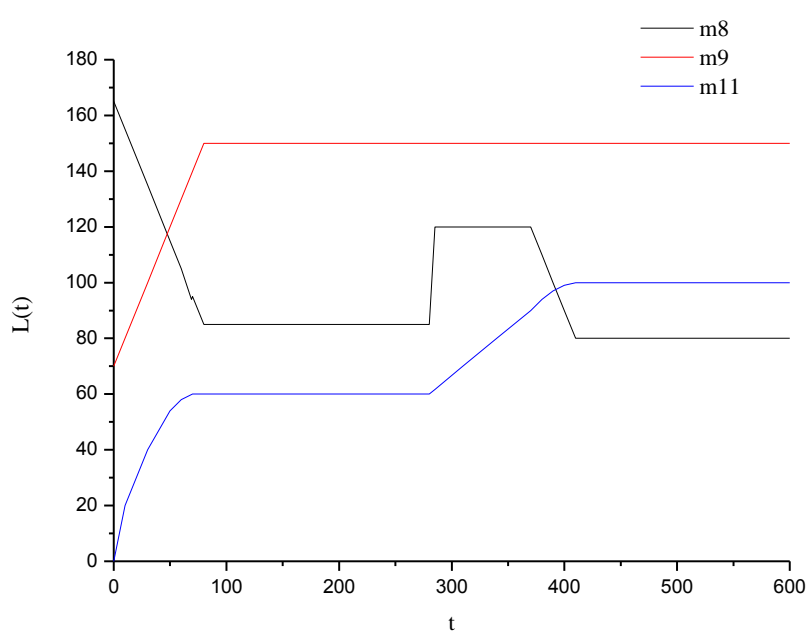

Figure 5: Liquid level changing curve when opening gauge of valve switches between $50 \%$ and $70 \%$.

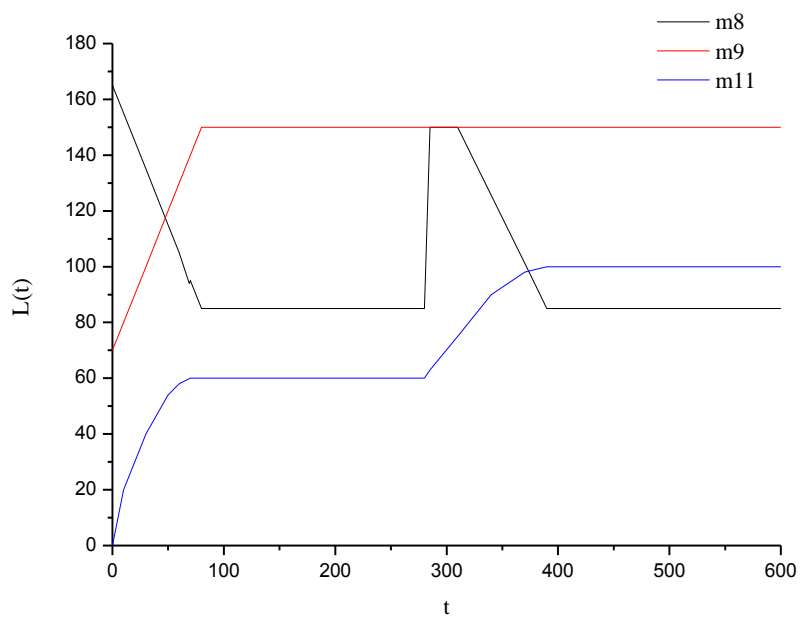

Figure 6: Liquid level changing curve when opening gauge of valve switches between $50 \%, 70 \%$ and $90 \%$.

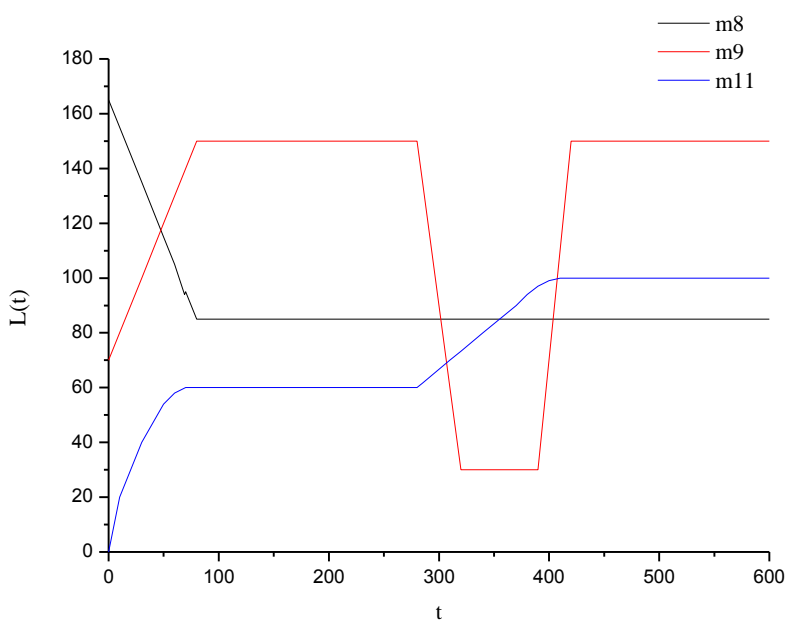

Figure 7: Liquid level changing curve when the state of loop heat pump changes. 


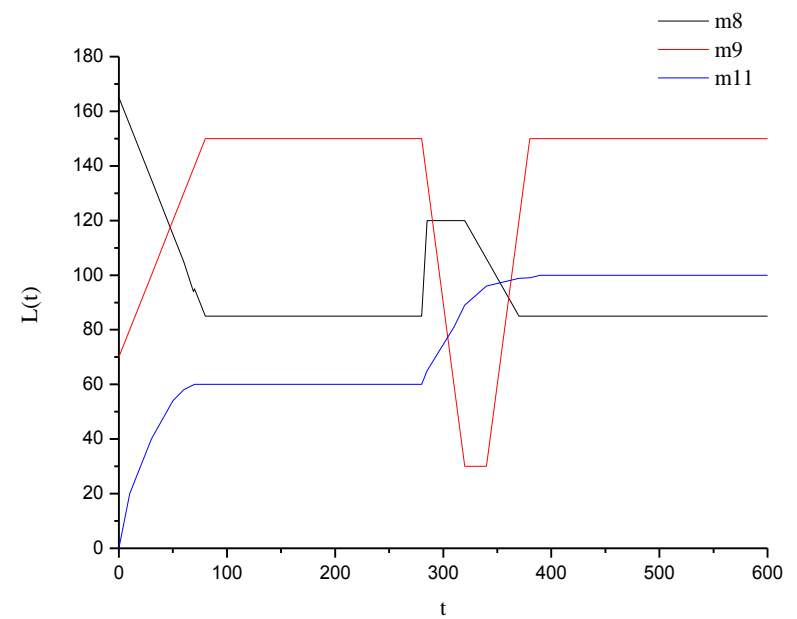

Figure 8: Liquid level changing curve when opening gauge of valve switches between $50 \%$ and $70 \%$, at the same time, the state of loop heat pump also changes.

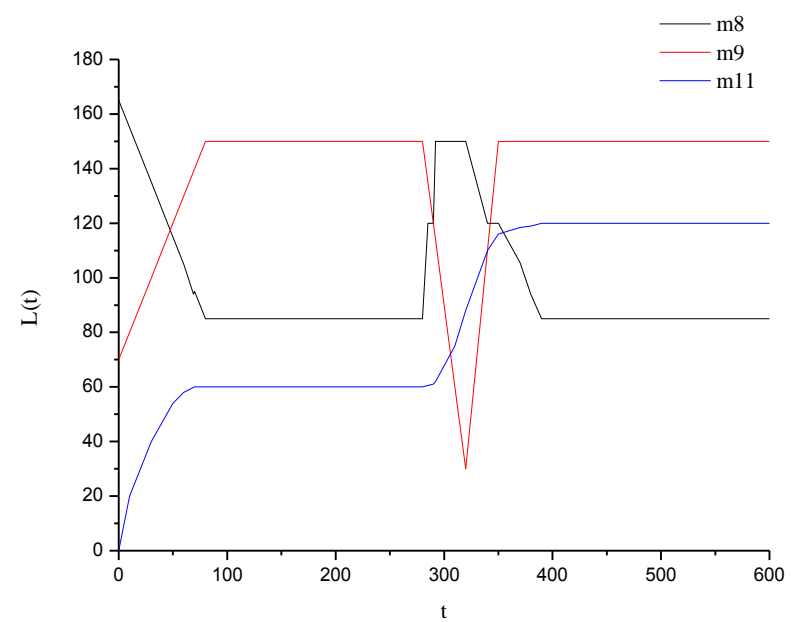

Figure 9: Liquid level changing curve when opening gauge of valve switches between $50 \%, 70 \%$ and $90 \%$, at the same time, the state of loop heat pump also changes.

\section{CONCLUSION}

This paper has set up a new hybrid Petri net model for industrial production logistics hybrid systems and has reached following conclusions by taking one industrial DFM solvent recovery process as the modelling object to study:

(1) A new hybrid Petri net model has been established based on common hybrid Petri net and with a combination of differential Petri net and controlled Petri net, and simulation calculation has been made with Java language. This model can well describe the state and control behaviour of the hybrid system and can unify the simulation and analysis under one model framework.

(2) DMF solvent recovery process is taken as background, and this hybrid Petri model is adopted for modelling and simulation. Control and adjustment is based on simulation results, which has indicated that this model has very good guiding significance in industrial production logistics and can improve production efficiency and decrease waste of resources.

\section{ACKNOWLEDGEMENT}

This work was supported within a study on the construction of community service system in the perspective of the modernization of national governance (No. 601525S22039). 


\section{REFERENCES}

[1] Debevec, M.; Simic, M.; Herakovic, N. (2014). Virtual factory as an advanced approach for production process optimization, International Journal of Simulation Modelling, Vol. 13, No. 1, 66-78, doi:10.2507/IJSIMM13(1)6.260

[2] Wang, Y. R.; Chen, A. N. (2016). Production logistics simulation and optimization of industrial enterprise based on Flexsim, International Journal of Simulation Modelling, Vol. 15, No. 4, 732 741, doi:10.2507/IJSIMM15(4)CO18

[3] Balduzzi, F.; Giua, A.; Menga, G. (2000). First-order hybrid Petri nets: a model for optimization and control, IEEE Transactions on Robotics and Automation, Vol. 16, No. 4, 382-399, doi: $10.1109 / 70.864231$

[4] Flaus, J.-M.; Ollagnon, G. (1997). Hybrid flow nets for hybrid processes modelling and control, Maler, O. (Ed.), Hybrid and Real-Time Systems, HART 1997, 213-227, Springer, Berlin

[5] Li, H.-G.; Yu, J.-S. (2003). Hybrid systems in chemical process control and its Petri net-based descriptions, Computers and Applied Chemistry, Vol. 20, No. 5, 607-610

[6] Zhao, F.; Zhu, J.; Qiao, F.; Wu, Q. (2010). Energy consumption model of iron and steel enterprises process and its conversion to hybrid Petri nets, Systems Engineering, Vol. 28, No. 6, 70-75

[7] Zhao, F.; Zhu, J.; Qiao, F.; Wu, D. (2011). Application of hybrid Petri net in modeling of enterprise energy system, Industrial Engineering and Management, Vol. 16, No. 1, 108-113

[8] Zhang, Y.; Wang, J. (2011). Continuous process enterprises energy prediction model and its simulation, Computer Integrated Manufacturing Systems, Vol. 17, No. 7, 1526-1533

[9] Zhang, Y.; Wang, J. (2011). Model and simulation of enterprises production and energy consumption process based on continuous Petri net, Computer Integrated Manufacturing Systems, Vol. 17, No. 12, 2714-2722

[10] Wang, Q.; Wen, L.-Q.; Li, J.-X.; Ke, Y.-L.; Li, T.; Zhang, S.-J. (2015). Modeling and optimization for aircraft final assembly line based on Petri net, Journal of Zhejiang University (Engineering Science), Vol. 48, No. 7, 1224-1231

[11] Shu, Y.-Z.; Liu, Y.-P.; Peng, X.-H.; Chen, Z.-Y. (2010). Survey on object-oriented Petri net modeling, Computer Engineering and Design, Vol. 31, No. 15, 3432-3435

[12] Wang, W.-B.; Da, Q.-L. (2007). Remanufacturing supply chain modeling and analysis based on generalized stochastic Petri nets, System Engineering - Theory \& Practice, Vol. 27, No. 12, 56-61

[13] Le Bail, J.; Alla, H.; David, R. (1991). Hybrid Petri nets, Proceedings of the $1^{\text {st }}$ European Control Conference, 1472-1477

[14] Demongodin, I.; Audry, N.; Prunet, F. (1993). Batches Petri nets, Proceedings of the International Conference on Systems, Man and Cybernetics, Vol. 1, 607-617

[15] Caradec, M.; Prunet, F. (1998). Modelling of hybrid flexible production systems by coloured batches Petri nets, European Journal of Automation Systems, Vol. 32, No. 9-10, 1255-1269

[16] Demongodin, I.; Koussoulas, N. T. (1998). Differential Petri nets: representing continuous systems in a discrete-event world, IEEE Transactions on Automatic Control, Vol. 43, No. 4, 573 579, doi: $10.1109 / 9.665073$

[17] Koutsoukos, X. D.; He, K. X.; Lemmon, M. D.; Antsaklis, P. J. (1998). Timed Petri nets in hybrid systems: stability and supervisory control, Discrete Event Dynamic Systems, Vol. 8, No. 2, 137-173, doi:10.1023/A:1008293802713

[18] Balduzzi, F.; Menga, G.; Giua, A.; Seatzu, C. (1999). A linear state variable model for first-order hybrid Petri nets, Proceedings of the $14^{\text {th }}$ IFAC World Congress, Vol. J, 205-210

[19] Qu, J.-X.; Chen, J.-Z. (2009). Research progress in recovery and treatment of DMF-contained tannery wastewater, West Leather, Vol. 30, No. 21, 34-38

[20] Tian, P.; Pan, Z.-Y.; Zou, X.; Lin, C.-M. (2010). Inhibiting effect of DMF hydrolysis in DMF recycling system, Environmental Science \& Technology, Vol. 33, No. 2, 170-173

[21] Reis, A. H. (2016). Ad-hoc principles of "minimum energy expenditure" as corollaries of the constructal law. The cases of river basins and human vascular systems, International Journal of Heat and Technology, Vol. 34, Special Issue 1, S147-S150

[22] Zhao, S.-H.; Song, X.-J.; Zhang, J.-Z.; Liu, S.-Q.; Pei, N. (2007). Energy-saving recovery process of DMF from synthetic leather waste water, Chemical Industry and Engineering Progress, Vol. 26, No. 9, 1347-1350 